\title{
"SIM, SIM": A NOÇÃO DE METODOLOGIA DE PROJETO NO CAMPO DO DESIGN SOB O CRIVO DA NOÇÃO DE RESPONSABILIDADE EM DERRIDA
}

\author{
Alberto Cipiniuk, Dr \\ Pontifícia Universidade Católica do Rio de Janeiro (PUC-Rio) \\ cipiniuk@puc-rio.br \\ Fabiana Oliveira Heinrich, doutoranda \\ Pontifícia Universidade Católica do Rio de Janeiro (PUC-Rio) \\ fabianaheinrich@gmail.com \\ Wilson Silva Prata, doutorando \\ Pontifícia Universidade Católica do Rio de Janeiro (PUC-Rio) \\ wilsonprata@gmail.com
}

Resumo: Este ensaio propõe algumas reflexões a respeito da noção de metodologia projetual no Campo do Design sob o crivo da noção de responsabilidade para Jacques Derrida. Considerada frequentemente como a raison d'être do Campo em questão, isto é, um dos pressupostos para a formação da prática social intitulada Design, a metodologia projetual, um modus operandi, é antes de tudo uma noção construída. Conforme Derrida, toda noção é construída e apresenta implicações de entendimento e uso da ordem da responsabilidade que perpassam suas relações internas e externas imanentes às práticas sociais, à estrutura do Campo e seu espaço simbólico - e é isto o que aqui buscamos escrutinar na noção de metodologia projetual no Campo do Design.

Palavras-chave: Campo do Design, metodologia de projeto, Jacques Derrida, responsabilidade

\begin{abstract}
This essay proposes some reflections on the notion of project methodology in the Design Field under the scrutinity of the notion of responsibility to Jacques Derrida. Often considered as the raison d'être of the mentioned Field, that is, one of the prerequisites for the formation of the social practice named Design, the project methodology, a modus operandi, is first and foremost a built notion. According to Derrida, every notion is built and has implications regarding its understanding and usage according to the notion of responsibility that pervade its internal and external relations imanent to social practices, to the Field structure and its symbolic space - and this is what we seek to scrutinize here on the notion of project methodology in the Design Field.
\end{abstract}

Keywords: Design Field, project methodology, Jacques Derrida, responsibility. 
O Design não é a única prática social a desenvolver projetos e, consequentemente, o designer não é o único profissional a fazer uso de uma metodologia projetual como principal meio para sua atuação. A Arquitetura e as distintas Engenharias, por exemplo, também operam através da concepção projetual. Entretanto, observa-se que no Campo do Design a noção de metodologia projetual fazse presente não só na descrição operativa: ela é citada também como uma das maneiras de definir o próprio Campo. ${ }^{1}$

Segundo Cross (2004), a noção Design se define na crença de que este se desenvolve primeiro no plano ideal, para depois ser aplicado à prática, ou seja, trata-se do desenvolvimento de um projeto ou plano com embasamento metodológico para a solução de um problema concreto. Para o mesmo autor, metodologia projetual consiste do processo de desenvolvimento de um projeto, no qual o designer faz uso de diferenciadas técnicas para chegar a uma solução, considerando todas as características que o produto deverá apresentar a fim de atender satisfatoriamente a funções pré-determinadas. Logo, observa-se que 0 uso das expressões "desenvolvimento de um projeto com embasamento metodológico" e "processo de desenvolvimento de um projeto", não obstante uma breve variação sintática, apresenta um equivalente valor semântico. Além disso, o papel central da metodologia de projeto no Campo do Design pode ser verificado também através do uso de sinônimos como método, processo, projetação, palavras recorrentes no vocabulário aplicado à definição da atividade do designer. ${ }^{2}$ Deste modo, quais implicações esta proximidade de entendimentos traz ao Campo?

É fato que muitos agentes, em suas diferentes posições no Campo do Design, apresentam juízos variados quanto às definições do Campo, justamente em virtude dessas proximidades apresentarem-se confusas. De nossa parte, entendemos por Campo $^{3}$ do Design um espaço simbólico no qual os agentes lutam pela preservação de um jogo específico - a prática do Design na sociedade capitalista associada à acumulação de capital econômico, social, cultural e simbólico decorrente de trocas executadas dentro deste espaço. Essas relações, apesar de serem relativamente autônomas, não podem ser dissociadas das demais relações de poder que estruturam a sociedade e o próprio Campo. Assim, enquanto flexibilizações conceituais ou semânticas, elas podem ser sinônimo positivo de uma abertura do Campo a possíveis atualizações e expansões; entretanto, atentamos para o fato de que ao não prescindir de uma definição-base ou operacional, que oriente essas possíveis atualizações e expansões - que vale aqui ressaltar, são sempre decorrentes de ações políticas -, pode-se acabar por incutir ao Campo uma concepção próxima de uma cacofonia ou um niilismo conceitual.

Logo, em face a este quadro epistemológico contemporâneo, julgamos absolutamente necessárias algumas considerações acerca da supracitada noção de metodologia projetual no Campo do Design, principalmente no que tange a um entendimento desta a partir de uma esfera filosófica - neste caso considerando o

\footnotetext{
${ }^{1}$ Para maiores informações sobre este tema, ver HEINRICH, Fabiana Oliveira. Design: crítica à noção de metodologia de projeto. Dissertação de Mestrado. Orientador: Alberto Cipiniuk. Pontifícia Universidade Católica do Rio de Janeiro, Departamento de Artes e Design, 2013.

2 Idem, ibidem.

${ }^{3}$ BOURDIEU, Pierre. A Economia das Trocas Simbólicas. 5a edição. São Paulo: Perspectiva, 2009.
} 
pensamento de Derrida e a noção de responsabilidade 4 abordada pelo autor. A noção de metodologia projetual se mostra como um dos cânones que melhor serve para uma aproximação com os questionamentos lançados por Jacques Derrida, posto que a esta - construção arbitrária e operacional - transcende seu papel instrumental para assumir tanto um ethos quanto uma posição ontológica, ou seja, a razão de ser do Campo do Design e seus agentes. Com efeito, essa aproximação que se apresenta não busca uma liquidação das práticas do Campo, mas sim estabelecer uma crítica, colocar seus pressupostos sob novas bases teóricas para desconstruir, desmistificar, desnaturalizar aquilo que, em termos derridianos, escapa à responsabilidade e incorre no cálculo.

Antes de adentrar à noção de responsabilidade e usarmos seu crivo para pensar a noção de metodologia de projeto no Campo do Design, devemos esclarecer de que consiste a noção de desconstrução, tão cara ao pensamento de Derrida, posto que desta depende nosso entendimento do pensamento do autor. Duque-Estrada ${ }^{5}$ (2011) esclarece que a origem de um pensamento desconstrutivista não está necessariamente em Derrida, mas sim em Heidegger, quando este concebeu o que chamou de "destruição metafísica". Por "destruição metafísica", o autor definiu o ato de fazer com que conceitos que anteriormente eram associados às experiências de pensamentos dinâmicos reassumissem seu papel na tradição do pensamento ocidental, pois o autor considera que com o passar do tempo estes adquiriram um aspecto monolítico, isto é, tornaram-se engessados. Deste modo, ao invés de ferramentas para o pensar, estes conceitos dogmaticamente passaram a ser entendidos como estruturas semânticas estáveis - e isto precisava ser revisto.

Julgamos que a preocupação de Derrida pode ser estendida para o Campo do Design visto que, a exemplo do engessamento do pensar e da apropriação desse recurso epistemológico pelo discurso instrumental funcionalista, algo semelhante ocorreu com várias iniciativas e escolas que caracterizam o Campo, como, por exemplo, a Bauhaus. De uma iniciativa que originalmente se propunha libertadora e emancipadora, é possível observar que muitos dos objetos que hoje são caracterizados como tendo um "estilo Bauhaus" são, antes de tudo, empregados de modo político, isto é, como objetos de distinção social. ${ }^{6} \mathrm{O}$ mesmo pode ser dito de vários de seus ideais estéticos, como a importância de uma tipografia universal, que supostamente se comunicaria de modo indistinto para todos por ser precisamente clara em suas formas e usos. Contudo, esse tipo de representação fora apropriado politicamente pelos grandes conglomerados industriais de maneira que, nos dias de hoje, por conta de sua ampla e sistemática difusão, temos a tendência de associarmos uma tipografia sem serifa, de hastes simples e formas claras às empresas tecnológicas, grandes conglomerados financeiros e majors da indústria do entretenimento. ${ }^{7}$

\footnotetext{
${ }^{4}$ Noção descrita em DERRIDA, Jacques. 'Ulysses' Gramophone: Hear Say Yes In Joyce. Acts of Literature. Ed. Derek Attridge. New York: Routledge, 1992.

${ }^{5}$ Anotações da disciplina FIL2289 - Tópicos Especiais de Filosofia Contemporânea ministrada por Paulo Cesar Duque-Estrada na Pós Graduação da PUC-Rio. Rio de Janeiro: Pontifícia Universidade Católica do Rio de Janeiro, 2011.

${ }^{6}$ BOURDIEU, Pierre. 2009.

${ }^{7}$ Para maiores informações sobre este tema, consultar: ALMEIDA, Marcelo Vianna Lacerda de. A eficiência do signo gráfico empresarial: forma consagrada pelo campo do design nas instâncias da cultura visual moderna. Tese de Doutorado. Orientador: Alberto Cipiniuk. Pontifícia Universidade Católica do Rio de Janeiro, Departamento de Artes e Design, 2010.
} 
Aparte desta breve consideração acerca de questões formais, inserida à título de elucidação e exemplificação mais próxima aos pares do Campo do Design, o foco desse trabalho será a questão estrutural do Campo a partir da noção de metodologia projetual e uma possível aproximação desta com a noção de responsabilidade em Derrida, ou seja, para a defesa desse avizinhamento de natureza política e camuflado como neutro, entre o engessamento da metafísica ocidental, a noção de metodologia projetual e a noção de responsabilidade, se fazem necessárias algumas considerações acerca da supracitada posição da noção de metodologia projetual no Campo do Design.

Em entrevista cedida a Jean-Luc Nancy, denominada "Eating Well", or the calculation of the subject: an interview with Jacques Derrida, publicada no livro intitulado Who comes after the subject?, de 1991, Derrida discorre sobre a problemática do sujeito na Filosofia e sobre as implicações de tal pensamento. A partir do panorama a respeito dessa problemática, decorrente do questionamento do que haveria/quem viria após o sujeito ("who comes after the subject?"), e entre as variadas noções apresentadas e explicadas pelo filósofo na entrevista - algumas das quais abordaremos a seguir - uma das noções mais interessantes para a questão que aqui se propõe é, conforme supracitado, a noção de responsabilidade. Trazemos a questão da metodologia de projeto e o Campo do Design nesta perspectiva, pois o designer é um agente que faz uso político da metodologia, é um sujeito social, uma instância que guarda em si suas contradições - e, por isso, faz-se mister pensá-lo nestes termos. Entretanto, para explorar de maneira mais profunda essa relação, devemos primeiramente retornar para algumas noções derridianas complementares, como as noções de sujeito ${ }^{8}$, conceito $^{9}$, linguagem ${ }^{10}$, "sim, $\operatorname{sim}^{11}$ e da gramofonia ${ }^{12}$, a fim de proporcionar um claro entendimento da discussão aqui proposta.

Posto isso, principiamos pelo esclarecimento de Derrida acerca da inexistência de um sujeito definido e distinto, ou ainda uma noção de sujeito que dê conta de todos os usos e leituras que foram feitas a partir desse entendimento. O filósofo demonstra com isso que a questão de quem ou o quê vem após o sujeito implica uma opinião filosófica, uma doxa; a de que "o sujeito" pode ser claramente identificado como algo conciso e distinto. A confusão dessa doxa se baseia, em parte, na ideia igualmente equivocada de vários pensadores franceses do século passado, que ao tratarem da problemática da subjetividade, procuravam na verdade "liquidar" o sujeito. Nesse sentido, o termo liquidação era caracterizado como uma ilusão e uma ofensa, algo que, além de ser um despautério, deveria ser impedido, pois não se pode pensar na liquidação de um conceito. Derrida menciona que considera a noção e o ato de liquidar referentes à esfera da lei, da polícia, do crime, mas não à uma estratégia discursiva, pois há sempre a herança ao que precede a formação de um conceito: em tradução livre, o que vem sempre precede ("what comes always preceds").

Derrida, com base em Hegel $^{13}$, aponta ainda que é possível compreender o

\footnotetext{
${ }^{8}$ Noção descrita em DERRIDA, Jacques. "Eating well," or the calculation of the subject: an interview with Jacques Derrida; in Cadava, E; Connor, P; Nany, J-L: Who comes after the subject? Routledge. New York \& London, 1991.

${ }^{9}$ Idem, ibidem.

${ }^{10}$ Idem, ibidem.

${ }^{11}$ DERRIDA, Jacques. 1992.

12 DERRIDA, Jacques. 1991.

${ }^{13}$ DERRIDA, Jacques. 1991.
} 
sujeito como aquilo que sustenta em si mesmo sua própria contradição. Dessa forma, os diferentes sujeitos na tradição filosófica ocidental ainda podem ser compreendidos como noções relevantes para o entendimento destes mesmos sujeitos desde que estas noções estejam delimitadas a partir de uma malha referencial da abordagem utilizada, podendo ser está lógica, histórica, transcendental, psicanalítica, etc. Contudo, apesar dessas delimitações serem efetivas para compreender um pouco melhor as contradições que são colocadas pelas abordagens utilizadas, essas, por mais completas que sejam, nunca conseguiram dar conta da complexidade desse fenômeno. Derrida, após desvelar essa operação, conclui que nunca houve "o sujeito": o que há são textos sobre sujeitos. De qualquer forma, a limitação da doxa do sujeito se evidencia primeiramente por acreditar, na falta de um termo melhor, que o sujeito é o mesmo "personagem", para os diferentes pensadores. Um sujeito clássico, com seus limites definidos, mas que na verdade nunca existiu enquanto tal, pois esse foi sempre um termo em disputa. ${ }^{14}$

Além disso, Derrida define que a noção de conceito, assim como qualquer outra noção, é sempre uma noção construída. Não há a possibilidade da concepção de uma definição a priori, anterior às instâncias humanas, pois todo o conhecimento, assim como a própria linguagem, são construções oriundas do trabalho intelectual humano. Logo, por inserirmo-nos nesta esfera de construção, outras noções tangentes, como rigor e reflexão acabam por vir à tona, pois estas caracterizam aspectos necessários a uma construção conceitual. Ainda, a noção de método também acaba por vigorar neste mesmo panorama, pois para a concepção de qualquer construção, faz-se imprescindível o uso de um passo-a-passo ordenado, minimamente lógico, e quase sempre operado por um sujeito, uma identidade necessária para calcular a sua concepção. Tem-se, portanto, que os conceitos não são construções imanentes, ainda que sua estruturação possa vir a surgir dessa forma, visto que, sob vários aspectos, a maioria dos fenômenos é anterior ao entendimento destes a partir da instância do ser.

A partir desse entendimento da noção de conceito, podemos compreender com mais clareza, então, a supracitada noção de sujeito para Derrida. Por se tratar de um conceito - conforme já explicitado - imediatamente partimos do pressuposto de que esta é uma construção social. Logo, não há a possibilidade da existência de um sujeito a priori, ou melhor, de uma identidade genuína livre de qualquer influência interna ou externa ao sujeito propriamente dito. Há, apenas, a noção de sujeito enquanto uma construção desenvolvida a partir de um contexto, a partir de um espaço-tempo demarcado, o qual definirá suas próprias instâncias delimitadoras e às quais ele retomará, através de uma relação, uma presença a si. ${ }^{15}$

Ante isso, é possível constatar que a relação entre o ser e a existência é ausente em todas as noções de seres que tentam explicar essa relação a partir da subjetividade do sujeito. Uma forma de superar essa limitação é a noção de Dasein proposta por Heidegger, pois ela sustenta um ser que não se limita a ser sujeitado. ${ }^{16}$ Nesse sentido, o Dasein, o ser no mundo, é antes de tudo um lançamento. Esse ser jogado ao mundo é anterior à subjetividade, pois antes da subjetivação há o próprio existir. Também é anterior à objetividade, pois é um entendimento de re-apropriação e expropriação distinto e muito mais basal que o sujeito ou o projeto, que presumem substância,

\footnotetext{
${ }^{14}$ DERRIDA, Jacques. 1991.

15 Idem, ibidem.

${ }^{16}$ Idem, ibidem.
} 
presença, algo já formado. ${ }^{17} \mathrm{Em}$ se tratando da temática da entrevista em questão, essa perspectiva parece dizer que o relevante não é o que vem "após" o sujeito, mas o que vem "antes" dele. Logo, Derrida concorda parcialmente, conquanto esteja claro que esse "antes" não é de ordem cronológica ou ontológica transcendental. O que antecede o sujeito não é um outro sujeito ou unidade semântica, mas a própria estrutura referencial. ${ }^{18}$ Assim, usamos essa linha de pensamento para investigar o que vem antes do sujeito, mas mantemos a problemática do sujeito para a questão da responsabilidade do designer e a metodologia projetual visto que, por mais que o sujeito seja posterior ao lançamento do ser no mundo, é enquanto sujeitos relativamente formados e construídos que os agentes sociais atuam no Campo do Design e colocam em prática os processos legitimados por essa instância.

Ainda, faz-se relevante discorrer aqui sobre a noção e a função da linguagem a partir deste ínterim. Por também ser uma construção do homem, a linguagem apresenta-se circunscrita e delimitada por questões de ordem conceitual, técnica e moral: i) conceitual, pois parte de uma unidade tida como verdadeira, ainda que arbitrária, para a sua definição; ii) técnica, enquanto forma delimitada e materialização circunscrita em determinado contexto; e iii) moral, pois seu uso sempre será constituído por uma ação, um pensamento da ordem do cálculo, visto que será concebido por um sujeito situado em determinado espaço-tempo, o qual provavelmente prescindirá de delimitações políticas e de poder, por exemplo. Logo, sempre haverá um enclausuramento ${ }^{19}$ no uso da linguagem, do discurso; ou seja, o pensamento a ser expresso pelo ser humano sempre será materializado através de um sistema linguístico disponível, o qual será uma construção social e, por ser uma construção, não se caracteriza como capaz de prover a verdade (pois sendo um traço ${ }^{20}$, há somente uma nova indicação de verdade).

Imediatamente, é a partir desta clarificação acerca da posição da linguagem que podemos discorrer brevemente sobre o "sim-sim"21, um entendimento que permite avançar a questão da responsabilidade mesmo ante às limitações relatadas. Desenvolvida a partir do texto de 'Ulysses' Gramophone: Hear Say Yes in Joyce, de 1992, a noção do "sim, sim" consiste de um aceite prévio, primeiramente nãoconsciente, a partir da própria linguagem que é enclausurante, com a finalidade de i) colimar a presença do sujeito: em um primeiro momento, o primeiro "sim"; e ii) de fazê-lo consciente de sua escolha: no segundo momento, o segundo "sim". Com o "sim, sim", o sujeito levanta as questões do quem? e do o quê?, questões básicas

\footnotetext{
17 Idem, ibidem.

${ }^{18}$ DERRIDA, Jacques. 1991.

19 Idem, ibidem.

${ }^{20}$ A noção de différance (ver nota 24) trabalha a partir do espaçamento, atrelada à temporalização, existente no próprio jogo de diferir e diferenciar, em que se produz as diferenças e seus efeitos. Isso faz com que qualquer elemento presente não esteja plenamente presente, pois toda presença é tributária de uma identidade a si, visto que essas diferenças são estabelecidas nas relações dentro do sistema de diferenciação a que Derrida vai chamar de Escritura. Nesse sentido, Santiago (1979: 83) entende como traço "a différance que abre o aparecer à significação", percepção que se evidencia e que estabelece as conexões entre essas diferenciações, mas que não é algo fixo e imutável, pois como efeito da escritura, este é um sentido percebido de um contínuo "sendo". Assim, o traço é o desaparecimento da presença, de algo que foi (sem se saber plenamente exatamente o que) mas que já é outra coisa, uma verdade sempre postergada e adiada.
}

${ }^{21}$ Idem, ibidem. 
quando à delimitação de noções. O "sim, sim" antecede o sujeito, por seu caráter inconsciente, mas também, é a partir dele que o sujeito se coloca, se mostra enquanto instância pensante: é uma versão prévia da aceitação. Deste modo, o "sim, sim" carrega uma repetição: ele confirma e promete, principalmente instâncias da ordem da cultura, da tradição, de conceitos, as quais dependem do contexto em que é empregado. Ainda, ele apresenta-se enquanto parte da noção de gramofonia, a qual, oriunda do texto de Ulysses, caracteriza a concepção de que nada morre, tudo se propaga. A gramofonia registra o que é ouvido, lido, falado, partindo de uma fixação da voz na escrita e de uma fixação da escrita na voz.

É importante observar que esse "sim, sim", e esse se sujeitar do sujeito, ocorrem mesmo quando há o não. Dizer não é responder sim ao primeiro "sim, sim", pois a linguagem já invadiu o sujeito, o primeiro "sim", é um impacto hegemônico a revelia do sujeito: sem esse primeiro "sim", não há alteridade; sem alteridade, não há singularidade; e sem singularidade, não há subjetividade, logo não há sujeito. Portanto, sobre o "sim, sim" em relação ao sujeito: no primeiro "sim" nós somos afetados, esse afeto faz com que nós nos reconheçamos como herdeiros; no momento em que respondemos ao segundo "sim", que pode ser um não, um talvez ou uma resposta postergada, evidencia-se nossa posição em relação à herança de diferenciações que acabamos por herdar. Dessa maneira, o sujeito deve ser pensado a partir do segundo "sim", pois se ele é o que carrega em si suas próprias contradições, só existe essa possibilidade a partir desse segundo momento. É aí que se instauram as instâncias de autonomia, de responsabilidade, de (reconhecimento da) alteridade, de referência e presença de si, enfim, de identidade.

Com efeito, é a partir da noção do "sim, sim" que adentramos à noção da responsabilidade derridiana, ideia central para o artigo aqui apresentado. Sumarizando o que foi até aqui exposto, para Derrida, a responsabilidade do ser humano antecede também ao sujeito, estando diretamente ligada ao "sim, sim". Para ele, a noção de responsabilidade sempre implica um sujeito e, consequentemente, a construção, a estrutura desse sujeito, não havendo, portanto, uma responsabilidade verdadeira ou $a$ priori. No "sim, sim" antes de se formar como sujeito, já há uma acolhida da linguagem e tudo que chega a esse sujeito ainda em formação, espera dele um sim. Dessa maneira, por já estar determinada pelo meio, esta responsabilidade estará sempre sujeita ao seu contexto, ao enclausuramento da linguagem empregada, não se caracterizando como um conhecimento universal a ser alcançado ou seguido. A relevância dessa constatação consiste em demonstrar que, ao pensar a partir da desconstrução, é inequívoco que a responsabilidade existe de modo anterior ao sujeito, tratando-se assim de uma responsabilidade tributaria a um chamado. A relação a si é impossível, e por ser impossível é que ela ocorre - se fosse possível uma relação a si próprio, seria uma eterna repetição do mesmo. Não é o sujeito que constrói a responsabilidade durante ou após sua formação, na subjetivação e exteriorização de suas práticas e suas contradições, essa responsabilidade é consequência de uma instância anterior. Por isso, quando nos referimos a noção de responsabilidade em seu entendimento vulgar, faz-se necessário um enclausuramento do discurso, que consiste em negar partes da gramofonia em busca de um sentido tópico, momentâneo.

Ainda, a responsabilidade a que se refere Derrida, estará incutida de urgência ${ }^{22}$

${ }^{22}$ DERRIDA, Jacques. 1991. 
e precipitação ${ }^{23}$ : urgência enquanto a necessidade visceral de um posicionamento; precipitação enquanto a delimitação espaço-tempo do que é abordado. Desse modo, Derrida aponta que não há responsabilidade que não deva passar no escrutino do incalculável e do indecidível. Quanto ao primeiro ponto pelo qual deve passar a responsabilidade, o incalculável é tributário da relação entre o todo e a parte, do universal e o particular, e da incomensurável distância entre esses polos. Assim, haverá sempre algo que não coube nas considerações e nas ações. Já o indecidível se mantém em razão do adiamento da chegada do sentido, como por exemplo, no caso dos conceitos, que devem sempre estar em aberto sob o risco de estagnarem e se tornarem unidades autorreferentes, arbitrárias e hegemônicas. De modo que é possível concluir que tudo o que é dito ou escrito nunca é apresentado em sua totalidade, em sua complexidade real, há sempre o incalculável e o indecidível impossíveis de serem expressados no que foi "calculado" e "decidido". Decorrente disto, recaímos neste enclausuramento, o qual consiste de uma repetição do mesmo em razão dessa diferença - entre o calculado e o incalculável, entre o decidível e o indecidível, a que Derrida chamará différance ${ }^{24}$ - uma retomada que não necessariamente repensa a instância, o objeto em questão. ${ }^{25}$

Assim, sendo o sujeito uma instância de questões, preso na imanência de um discurso, que não deve ser refém do cálculo, mas que é cálculo, considera-se que o sujeito é o questionador que busca respostas. Ante esse abismo que há entre a urgência e a precipitação, Derrida busca sublinhar uma estrutura sacrificial pois entende esta como o espaço deixado no discurso, na estrutura, na cultura, para um uso não criminal da morte. Essa estrutura é que permite avançar nessas questões mantendo em aberto sua indeterminação, pois sacrifício é levar à morte outras experiências que não sejam a da busca de verdades. Tal perspectiva deixa claro que toda cultura humana se funda em uma estrutura sacrificial, ou sacrificação ${ }^{26}$, conforme tradução proposta no supracitado curso, e que, além disso, tudo que é metafisico possui uma estrutura sacrificial. O sujeito, para resolver seus questionamentos, busca estabelecer uma lógica na gramofonia, e para isso se sacrifica e sacrifica outras partes do discurso e nesse processo, acaba recorrendo ao cálculo, estabelecendo fórmulas narrativas que viram a compor a estrutura da própria realidade. O sujeito é investimento e apropriação. Tudo entra em sua lógica, mas para isso ele precisa se assujeitar a própria estrutura que criou por suas práticas e seu discurso. A estrutura

\footnotetext{
${ }^{23}$ Idem, ibidem.

${ }^{24}$ A différance, nem uma palavra, nem um conceito, é uma marca muda que se lê mas não se ouve (a pronúncia é a mesma da palavra différence, "diferença" em francês, a alteração na grafia não muda a pronúncia). Derrida a apresenta como estratégia para o pensar, colocando em questão o valor da presença, da mesma maneira em que sua grafia coloca em questão a predominância da fala em relação à escrita. Dessa forma, situa sua crítica no interior da problemática do signo, ao diferir e diferenciar seu aspecto polissêmico. Assim, ao desvelar seu caráter provisório e arbitrário, demonstra que o signo só é pensável a partir da presença a que ele difere, no espaço e no tempo. A différance então abre mão do predicado da essência e da existência ao focar no valor da presença, discernindo a temporalização e o espaçamento que se faz necessário para a manutenção da distância implícita entre o signo e o significado e demais oposições binárias da metafísica ocidental. A desconstrução, operando a partir dos espaços identificados pela différance, consiste em demonstrar essa distância no coração da presença e o arbitrário de todo processo de significação.

${ }^{25}$ Idem, ibidem.

${ }^{26}$ DERRIDA, Jacques. 1991.
} 
sacrifical se trata, portanto, de um espaço que permite a ingestão, incorporação ou introjecção dos corpos. O sujeito é responsável pelo outro antes de ser responsável por ele mesmo, e essa assertiva deve ser levada em conta ante o fato de que os papéis dados, de designer, cliente ou usuário, são arremedos, enclausuramento de seres lançados no mundo. São definições tributárias do cálculo, papéis insuficientes ante a responsabilidade que cabe ao sujeito ante o outro.

Desse modo, emerge a questão: como e quando decidir? Se toda conclusão é precipitada, e se não há como não responder o segundo "sim" sem deixar de considerar o que está além do cálculo e da decisão, como que são possíveis decisões responsáveis? Para Derrida, esses momentos ocorrem na singularidade. O sujeito absorve o objeto para si, o cálculo do outro. Introjetar o outro é a lógica da subjetividade, porém é preciso lembra da responsabilidade de dar margem para o outro ser outro. Mas, como as relações não são estanques, esse outro que se introjeta é sempre um que se foi, resultando que esse trabalho é uma forma de luto, pois lida com a ausência deixada pelos rastros. A responsabilidade, ante essa decisão que deve ser tomada, mas que é incindível sem recair no cálculo, é uma vigília, uma agonia do pensar. Parar esse processo é cair no dogmatismo.

A responsabilidade começa a declinar quando cedemos a tentação do cálculo, quando se despreza as nuances. Assim, é possível entender a responsabilidade como uma tentativa de enxergar janelas no enclausuramento, pois somente dentro de um horizonte interpretativo é possível identificar os momentos de singularidade, da responsabilidade que não se pode fugir. O momento da decisão é o momento da nãoexperiência, pois se estamos projetados em situações, situações essas, prévias a nós, é somente no impasse que se torna possível construir a filosofia da responsabilidade.

A partir deste corpus derridiano, podemos considerar que as implicações da responsabilidade derridiana junto à noção de metodologia projetual no Campo do Design acabam por apresentar-nos duas problemáticas: a primeira, de ordem epistemológica e, a segunda, de ordem moral.

A problemática de ordem epistemológica configura-se a partir do uso e da legitimação, pelos agentes internos e externos do Campo em questão, da noção de metodologia de projeto como definidora do Campo do Design, da noção enquanto $t_{a}{ }^{27}$ na definição de uma prática social, noção naturalizada, mas que necessariamente não caracteriza a singularidade de modo responsável. Já sabemos que para Derrida, conceitos não apresentam verdades absolutas, entretanto, muitos agentes do Campo os enxergam enquanto tal e os aplicam desta forma. Logo, o emprego da noção de metodologia de projeto enquanto definidora do Campo do Design acaba por delimitar o próprio Campo de forma insuficiente, incipiente, por demais restrita, pois um Campo não pode ser determinado apenas, ou melhor, prioritariamente, por um modus operandi, afinal sua existência é justificada pela consonância de outros fatores como noções básicas da área, seu papel social e as instâncias para além da formação e da produção, por exemplo. Além disso, a noção de responsabilidade derridiana torna-se palpável ao observarmos uma aceitação inconsciente por parte do primeiro e, neste caso, também do segundo "sim": por não duvidar do que lhe é apresentado, por aceitar o conceito enquanto verdade universal, o sujeito - neste caso, o designer - , ao não questionar sua própria forma de pensamento e sua própria forma de expressão,

${ }^{27}$ DERRIDA, Jacques. 1991. 
não questiona também sua própria responsabilidade e apresenta-a enquanto verdade máxima, difundindo-a em suas instâncias de circulação e esperando o mesmo comportamento por parte de seus pares.

Já a segunda problemática, da ordem moral, recai num próprio enclausuramento do Campo em noções equivocadas e da ordem do cálculo que, não considerando propriamente as nuances, as différances de cada aspecto do Campo, acabam por ditá-las como verdade, como um imperativo a ser seguido sem o mínimo resquício da possibilidade de uma dúvida, da possibilidade de uma revisão. Esta problemática de ordem moral não se apresenta negativa apenas para o Campo, mas também e, principalmente, para os agentes que a empregam. Ao empregá-la de forma sistemática em seus usos teóricos e práticos, precipitadamente e com urgência, observa-se uma sacrificação, uma redução tanto do sujeito quanto do "objeto" a fundamentações erroneamente naturalizadas como teórico-prática e, possivelmente, politicamente (in)corretas. Neste caso, não se trata somente da questão epistemológica do Campo e da sacrificação do pensamento de seus agentes enquanto profissionais: trata-se da sacrificação, do enclausuramento em bases incertas de toda uma forma de pensar a totalidade de uma prática social e a totalidade de pensamento dos agentes desta prática, sendo que esta influência ao pensamento pode não reduzirse somente ao âmbito profissional, mas também a outros âmbitos das vivências desses agentes, afinal, conforme já explicitado, o "sim, sim" e a nossa necessidade de conceituar o nosso redor constituem-se de ações praticamente inconscientes diante de sua naturalização.

Derrida não procura negar certas autoridades, mas sim, desnaturalizar teorias e abordagens desse tipo e, assim, demonstrar seu arbitrário. Por mais que a lógica do sujeito seja a ordem do cálculo, e por isso mesmo, dos imperativos categóricos - das máximas para reger o pensamento e o comportamento de todos os sujeitos -, felizmente, somos mais que sujeitos, somos seres projetados no mundo que antes mesmo do primeiro "sim" já somos pura possibilidade. Os rastros dessas possibilidades permitem outras formas de imperativos, ainda que imperativos, mas não necessariamente categóricos; hipotéticos, por exemplo, imperativos que carregam uma condicionante, um "se".

Assim, a questão da metodologia projetual passa por esse ponto, da obrigação de proteger e respeitar a "outridade do outro" ("other's otherness"). De modo que uma metodologia não pode ser uma fuga dessa responsabilidade, o argumento de que a metodologia foi seguida não pode ser usada para eximir a responsabilidade do designer para consigo, para com seu trabalho e, acima de tudo, para com o outro.

Se toda responsabilidade do sujeito, passa, portanto, primeiramente, por reconhecer que toda conclusão é precipitada, é elucidativo o exemplo da figura do tirano que, graças ao poder por este acumulado, pode ser entendido como o ser que não possui responsabilidade. Logo, para o tirano não há indecisão, este sempre sabe como agir, já que seus atos "não têm" consequências. Ter responsabilidades é ter olhos a si mesmo, e reparar a gramofonia e reverberação que nos constitui, coisa que o tirano não faz. Logo, achar que na produção é possível esgotar todas as possibilidades e ressignificações que as instâncias de circulação e consumo abrem para com o objeto representa um esforço de sequestro da alteridade do outro sustentado por uma suposta autoridade que o Design possui - certamente virá ao pensamento do leitor alguns, senão muitos, "designers tiranos" de sua convivência próxima. Essa 
autoridade encontra-se em um lugar simbólico, não é uma autoridade concedida ao designer, é o que consideramos aqui como "designer tirano" que recorre a essa autoridade para justificar seus arbitrários e denegar seus interesses. Cria-se de modo despótico um lugar da verdade, dissociado das demais práticas, o que pode ser considerado um pensamento tirânico, pois este desconsidera as consequências de suas ações e de seus atos por colocar toda a responsabilidade em seu modus operandi. Seguir de modo mecânico a metodologia é seguir axiomas, é cair na tentação do cálculo, sendo que a responsabilidade se encontra justamente em uma anterioridade ao cálculo, nas fronteiras de uma definição e no uso desta definição de metodologia projetual.

Devemos sempre atentar ao fato histórico de que a metodologia projetual não é uma chamada de um não-lugar: ela possui uma história, é um postulado datado. Ela responde a um chamado do sujeito e seu resultado gera um outro chamado. Assim, observa-se que a noção derridiana de responsabilidade, quando pensada junto da noção de metodologia projetual no Campo do Design, ajuda-nos a identificar as implicações da posição teórico-prática contemporânea do Campo em questão e a visualizar possíveis abordagens para uma outra maneira de pensar o Campo. A noção de responsabilidade de Derrida não se caracteriza como uma salvação para os problemas da praxis e da teoria do Campo do Design - não é à toa que a desconstrução não deve ser vista como um método, mas uma estratégia para o pensar -; visto que o que ela demonstra é a possibilidade e a necessidade de modificar o status quo diante de uma recolocação de noções e prioridades, nos ajudando a ouvir a polifonia ${ }^{28}$ para que atendamos de modo responsável, dentro dos limites de cada ação, aos chamados dos múltiplos agentes pertencentes interna e externamente ao Campo, afinal designers produzem para aqueles que muitas vezes nem sabem o que é Design - sejam estes agentes internos ou externos ao Campo.

\section{REFERÊNCIAS}

ALMEIDA, Marcelo Vianna Lacerda de. A eficiência do signo gráfico empresarial: forma consagrada pelo campo do design nas instâncias da cultura visual moderna. Tese de Doutorado. Orientador: Alberto Cipiniuk. Pontifícia Universidade Católica do Rio de Janeiro, Departamento de Artes e Design, 2010.

BOURDIEU, Pierre. A economia das trocas simbólicas. 5a edição. São Paulo: Perspectiva, 2009.

CROSS, Nigel. Desenhante: pensador do desenho. Santa Maria: sCHDs Editora, 2004.

DERRIDA, Jacques. "Eating well," or the calculation of the subject: an interview with Jacques Derrida; in.: Cadava, E; Connor, P; Nany, J-L: Who comes after the subject? Routledge. New York \& London, 1991.

'Ulysses' Gramophone: Hear Say Yes In Joyce. Acts of Literature.

Ed. Derek Attridge. New York: Routledge, 1992.

DUQUE-ESTRADA, Paulo Cesar. Derrida e o pensamento da desconstrução: o redimensionamento do sujeito, in.: Cadernos IHU ideias, ano 8 - № 143. São Leopoldo: Unisinos, 2010.

${ }^{28}$ DERRIDA, Jacques. 1992. 
Desconstrução e incondicional responsabilidade in Revista CULT, № 117. Disponível em: http://revistacult.uol.com.br/home/2010/03/desconstrucao-eincondicionalresponsabilidade/Data de acesso: 30 de Novembro de 2011.

FIL2289 - Tópicos Especiais de Filosofia Contemporânea.

Anotações da disciplina ministrada na Pós-Graduação da PUC-Rio. Rio de Janeiro:

Pontifícia Universidade Católica do Rio de Janeiro, 2011.

HEINRICH, Fabiana Oliveira. Design: crítica à noção de metodologia de projeto.

Dissertação de Mestrado. Orientador: Alberto Cipiniuk. Pontifícia Universidade Católica do Rio de Janeiro, Departamento de Artes e Design, 2013.

SANTIAGO, S. (Org.). Glossário de Derrida. Rio de Janeiro: Francisco Alves, 1976. 